\title{
Application of Scientific Approach to Improve Learning Activity Sub Theme 1 Students In Grade 3 SDN 2 Dimoro Year 2020
}

\author{
Kabul Ali Sumarah \\ SD Negeri 2 Dimoro \\ kabulali970@gmail.com
}

\section{Article History}

accepted $14 / 11 / 2020$

approved $21 / 11 / 2020$

published 26/11/2020

\begin{abstract}
The purpose of this research was to increase the activeness of learning sub-themes 1 characteristics of the living creatures of grade 3 students at SDN 2 Dimoro in the 2020/2021 school year through a Scientific approach. The type of research conducted is Class Action Research (PTK) of three cycles, with each cycle consisting of one meeting. The stages of each cycle are planning, implementation, observation and reflection. Data collection of learners' learning activeness is carried out during pre-cycle activities, cycle 1, cycle 2, and cycle 3 using instruments in the form of observation sheets and questionnaires at the end of each activity. The observations showed that the level of learning activeness of all learners was less active during pre-cycle, quite active in cycle 1, active in cycle 2, and very active in cycle 3 . The observations showed an average score of learners' learning activeness in pre-cycle of 10, cycle 1 of 15.11 , cycle 2 of 20.44, and cycle 3 of 24.44 .
\end{abstract}

Keywords: Scientific Approach, learning activity

\begin{abstract}
Abstrak
Tujuan penelitian ini adalah untuk meningkatkan keaktifan belajar sub tema 1 ciri-ciri makhluk hidup peserta didik kelas 3 SDN 2 Dimoro tahun ajaran 2020/2021 melalui pendekatan Saintifik. Jenis penelitian yang dilakukan adalah Penelitian Tindakan Kelas (PTK) sebanyak tiga siklus, dengan setiap siklusnya terdiri dari satu pertemuan. Tahapan setiap siklusnya adalah perencanaan, pelaksanaan, observasi dan refleksi. Pengumpulan data keaktifan belajar peserta didik dilaksanakan ketika berlangsung kegiatan pra siklus, siklus 1 , siklus 2, dan siklus 3 menggunakan instrumen berupa lembar observasi dan angket pada setiap akhir kegiatan. Hasil observasi menunjukkan tingkat keaktifan belajar seluruh peserta didik kurang aktif pada saat pra siklus, cukup aktif pada siklus 1, aktif pada siklus 2, dan sangat aktif pada siklus 3. Hasil observasi menunjukkan skor rata-rata keaktifan belajar peserta didik pada pra siklus sebesar 10, siklus 1 sebesar 15,11, siklus 2 sebesar 20,44, dan siklus 3 sebesar 24,44.
\end{abstract}

Kata kunci: Pendekatan scientifik, aktivitas peserta didik

Social, Humanities, and Education Studies (SHEs): Conference Series https://jurnal.uns.ac.id/shes

p-ISSN 2620-9284

e-ISSN 2620-9292 


\section{PENDAHULUAN}

Keaktifan peserta didik dalam kegiatan pembelajaran sangat menentukan tercapainya tujuan pembelajaran. Etin (2007: 23) mengungkapkan dengan peserta didik aktif maka ia akan berusaha menggali informasi lebih dalam agar informasi yang mereka peroleh benar- benar mereka pahami sehingga tujuan dari proses belajar tercapai dengan baik. Melalaui hal tersebut peserta didik terlatih untuk cepat tanggap dan terbiasa berfikir kritis dalam menerima informasi yang diberikan oleh guru. Indikator keaktifan belajar yang seharusnya terlihat dari peserta didik ketika proses pembelajaran antara lain seperti yang dikemukakan oleh Dimyati \& Mudjiono (2006: 45) indikator keaktifan mencakup di antaranya: 1) Peserta didik mau mencatat atau sekedar mendengarkan penjelasan guru. 2) Peserta didik memperhatikan hal-hal yang dijekaskan oleh guru tentang materi pelajaran. 3)Peserta didik mencatat tugas yang diberikan dan mengerjakan tugas rumah. 4) Peserta didik mau berdiskusi dalam kelompok untuk memecahkan masalah yang berkaitan dengan pelajaran. 5) Peserta didik mampu melibatkan diri dalam proses Tanya jawab dalam kelas. 6) Peserta didik mau terlibat dalam menyimpulkan pembalajaran bersama guru dan teman siswa lainnya.

Akan tetapi kenyataannya di lapangan ketika proses pembelajaran sering terjadi masalah yaitu rendahnya keaktifan belajar peserta didik. Hal tersebut juga dialami pada proses pembelajaran di kelas 3 SDN 2 Dimoro tahun ajaran 2020/2021. Penyebab rendahnya keaktifan belajar peserta didik antara lain : 1) Kurangnya persiapan guru dalam penguasaan materi / bahan ajar. 2) Media pembelajaran yang digunakan kurang menarik dan kurang inovatif. 3) Metode pembelajaran yang digunakan hanya ceramah. 4) Belum menggunakan pendekatan pembelajaran yang sesuai. 5) Kegiatan pembelajaran masih didominasi oleh guru.

Jika tidak segera diatasi, masalah rendahnya keaktifan belajar akan menimbulkan dampak negatif yaitu : 1) Tidak tercapainya tujuan pembelajaran. 2) Turunnya minat belajar peserta didik. 3) Peserta didik sering membolos. 4) Peserta didik lebih memilih putus sekolah dan bekerja demi mendapatkan uang karena menganggap sekolah tidak bermanfaat. 5) Turunnya kualitas / mutu sekolah. 6) Turunnya kepercayaan masyarakat terhadap sekolah. 6) Sekolah tersebut akan kalah bersaing dengan sekolah lain. Solusi yang dapat dilakukan untuk mengatasi masalah rendahnya keaktifan belajar peserta didik menurut peneliti adalah melalui pendekatan Saintifik karena pendekatan saintifik sangat sesuai dengan implementasi kurikulum 2013 di sekolah dasar. Selain itu pendekatan saintifik dipandang lebih efektif hasilnya bila dibandingkan dengan pendekatan tradisional.

Berdasarkan latar belakang masalah, identifikasi masalah, dan analisis masalah yang telah diuraikan di atas, dirumuskan masalah "Bagaimana Keaktifan Belajar Dapat Ditingkatkan Melalui Pendekatan Saintifik Pada Peserta Didik Kelas 3 SDN 2 Dimoro Tahun Ajaran 2020/2021 Subtema 1( Ciri-Ciri Makhluk Hidup)" Sedangkan tujuan dari PTK ini adalah untuk meningkatkan keaktifan belajar melalui pendekatan saintifik pada peserta didik kelas 3 sdn 2 dimoro tahun ajaran 2020/2021 tema 1 ciriciri makhluk hidup.

\section{METODE}

Penelitian ini adalah penelitian tindakan kelas dengan model siklus yang menerapkan menerapkan pendektan Saintifik. Kurt Lewin memaparkan setiap siklus terdiri dari empat tahapan, yaitu: perencanaan tindakan, pelaksanaan tindakan, observasi, dan refleksi . Fokus data penelitian ini yaitu keaktifan belajar sub tema 1 ciri-ciri makhluk hidup peserta didik kelas 3 SDN 2 Dimoro tahun ajaran 2020/2021 pada pra siklus, siklus I, siklus II, dan siklus III. Sumber data dalam penelitian terdiri dari data primer dan data sekunder. 
Data primer merupakan data yang diberikan secara langsung oleh pengumpul data (Sugiyono, 2015: 308). Data primer dalam penelitian ini berasal dari hasil observasi, angket, nilai proses dan nilai hasil evaluasi peserta didik. Sedangkan data sekunder merupakan data yang diberikan secara tidak langsung oleh pengumpul data (Sugiyono, 2015: 308). Data sekunder penelitian ini yaitu dokumen berupa silabus dan RPP, buku presensi, buku induk dan jurnal.

Teknik pengumpulan data penelitian ini menggunakan instrument lembar observasi, angket, tes, serta dokumen. Menggunakan teknik analisis data deskriptif kualitatif. Model analisis kualitatif yang terkenal adalah model Miles \& Hubberman (1992: 20) yang meliputi : reduksi data (memilah data penting, relevan, dan bermakna dari data yang tidak berguna), sajian deskriptif (narasi, visual gambar, tabel) dengan alur sajian yang sistematis dan logis, penyimpulan dari hasil yg disajikan (dampak PTK dan efektivitasnya).

\section{HASIL DAN PEMBAHASAN}

Berdasarkan data keaktifan belajar sub tema 1 ciri-ciri makhluk hidup peserta didik kelas 3 SDN 2 Dimoro tahun ajaran 2020/2021 yang diperoleh melalui observasi selama proses pembelajaran menunjukkan hasil penelitian sebagai berikut :

Tabel 1. Nilai keaktifan peserta didik awal (Pra Siklus) tiap aspek

\begin{tabular}{ccccc}
\hline \multicolumn{5}{c}{ Nilai Setiap Aspek } \\
\hline $\begin{array}{c}\text { Perhatian } \\
\text { Peserta Didik }\end{array}$ & $\begin{array}{l}\text { Keberanian } \\
\text { Berpendapat }\end{array}$ & $\begin{array}{l}\text { Menghargai } \\
\text { Pendapat }\end{array}$ & $\begin{array}{l}\text { Pelaksanaan } \\
\text { Tugas }\end{array}$ & $\begin{array}{l}\text { Keberanian } \\
\text { Menjawab }\end{array}$ \\
\hline 14 & 11 & 22 & 22 & 21 \\
\hline
\end{tabular}

Nilai rata-rata keaktifan belajar dihitung menggunakan rumus :

\section{Jumlah perolehan skor seluruh siswa $\times 5$ aspek penilaian Jumlah total peserta didik}

$$
\frac{14+11+22+22+21}{9}=10
$$

Maka dapat disimpulkan bahwa nilai rata-rata keaktifan belajar pra siklus peserta didik kelas 3 SDN 2 Dimoro Kecamatan Toroh pada sub tema 1 ciri-ciri makhluk hidup termasuk dalam kriteria "kurang aktif" dengan perolehan nilai rata-rata keaktifan belajar sebesar 10.

Berdasarkan hasil data keaktifan belajar siklus 1 pada lembar observasi di atas, dapat diperoleh skor :

\section{Tabel 2. Nilai Keaktifan Belajar Siklus 1}

\begin{tabular}{|c|c|c|c|c|}
\hline \multicolumn{5}{|c|}{ Nilai Setiap Aspek } \\
\hline Perhatian & Keberanian & Menghargai & Pelaksanaan & Keberanian \\
\hline $\begin{array}{l}\text { Peserta } \\
\text { Didik }\end{array}$ & Berpendapat & Pendapat & Tugas & Menjawab \\
\hline 26 & 29 & 26 & 27 & 29 \\
\hline
\end{tabular}


Nilai rata-rata keaktifan belajar dihitung menggunakan rumus :

$$
\begin{aligned}
& \frac{26+29+26+26+29}{9} \\
& =15,11
\end{aligned}
$$

Maka dapat disimpulkan bahwa nilai rata-rata keaktifan belajar siklus 1 peserta didik kelas 3 SDN 2 Dimoro Kecamatan Toroh pada sub tema 1 ciri-ciri makhluk hidup termasuk dalam kriteria "cukup aktif" dengan perolehan nilai keaktifan belajar rata-rata kelas sebesar 15,11.

Berdasarkan hasil data keaktifan belajar siklus 2 pada lembar observasi di atas, dapat diperoleh skor :

Tabel 3. Nilai Keaktifan Belajar Siklus 2

\begin{tabular}{lcccc}
\hline $\begin{array}{l}\text { Perhatian } \\
\begin{array}{l}\text { Peserta } \\
\text { Didik }\end{array}\end{array}$ & $\begin{array}{l}\text { Keberanian } \\
\text { Berpendapat }\end{array}$ & $\begin{array}{l}\text { Nenghargai } \\
\text { Pendapat }\end{array}$ & $\begin{array}{l}\text { Pelaksanaan } \\
\text { Tugas }\end{array}$ & $\begin{array}{l}\text { Keberanian } \\
\text { Menjawab }\end{array}$ \\
\hline 35 & 34 & 36 & 44 & 35 \\
\hline
\end{tabular}

Maka dapat disimpulkan bahwa nilai rata-rata keaktifan belajar siklus 2 peserta didik kelas 3 SDN 2 Dimoro Kecamatan Toroh pada sub tema 1 ciri-ciri makhluk hidup termasuk dalam kriteria "aktif" dengan perolehan nilai rata-rata keaktifan mencapai 20,44 .

Nilai rata-rata keaktifan belajar dihitung menggunakan rumus :

$$
\begin{aligned}
& \frac{35+34+36+44+35}{9} \\
& =20,44
\end{aligned}
$$

Berdasarkan hasil data keaktifan belajar siklus 3 pada lembar observasi di atas, dapat diperoleh skor :

Tabel 4. Nilai Keaktifan Belajar Siklus 3

\begin{tabular}{lcccc}
\hline \multicolumn{5}{c}{ Nilai Setiap Aspek } \\
\hline $\begin{array}{l}\text { Perhatian } \\
\begin{array}{l}\text { Peserta } \\
\text { Didik }\end{array}\end{array}$ & $\begin{array}{l}\text { Keberanian } \\
\text { Berpendapat }\end{array}$ & $\begin{array}{l}\text { Menghargai } \\
\text { Pendapat }\end{array}$ & $\begin{array}{l}\text { Pelaksanaan } \\
\text { Tugas }\end{array}$ & $\begin{array}{l}\text { Keberanian } \\
\text { Menjawab }\end{array}$ \\
\hline 44 & 43 & 45 & 44 & 44 \\
\hline
\end{tabular}

Nilai rata-rata keaktifan belajar dihitung menggunakan rumus :

$\frac{44+43+45+44+44}{9}$

$=24,44$ 
Maka dapat disimpulkan bahwa nilai rata-rata keaktifan belajar siklus 2 peserta didik kelas 3 SDN 2 Dimoro Kecamatan Toroh pada sub tema 1 ciri-ciri makhluk hidup termasuk dalam kriteria "Sangat aktif" dengan perolehan nilai rata-rata keaktifan mencapai 24,44.

Tabel 5. Indikator pencapaian belajar minimal

\begin{tabular}{ll}
\hline Rentang Nilai Keaktifan & Kriteria \\
\hline $1-5$ & Sangat Kurang Aktif \\
\hline $6-10$ & Kurang Aktif \\
\hline $11-15$ & Cukup \\
\hline $16-20$ & Aktif \\
\hline $21-25$ & Sangat Aktif \\
\hline
\end{tabular}

Tabel 6. Perbandingan Skor Keaktifan Belajar Rata-rata Pra siklus, Siklus 1, Siklus 2, Siklus 3

\begin{tabular}{llll}
\hline \multicolumn{4}{c}{ Skor Tingkat Keaktifan Belajar Rata-Rata } \\
\hline \multirow{2}{*}{ Pra siklus } & Siklus 1 & Siklus 2 & Siklus 3 \\
\hline 10 & 15,11 & 20,44 & 24,44 \\
\hline
\end{tabular}

Berdasarkan hasil penelitian penerapan pendekatan saintifik untuk meningkatkan keaktifan belajar pada sub tema 1 ciri-ciri makhluk hidup peserta didik kelas 3 sdn 2 dimoro tahun ajaran 2020/2021 di atas, maka dapat disimpulkan sebagai berikut:

Penerapan pendekatan saintifik dapat meningkatkan keaktifan belajar pada sub tema 1 ciri-ciri makhluk hidup peserta didik kelas 3 SDN 2 Dimoro Kecamatan Toroh, Kabupaten Grobogan, Jawa Tengah tahun ajar 2020/2021.

Keaktifan belajar Peserta didik pada pelaksanaan pra siklus menunjukkan kriteria kurang aktif dibuktikan dengan perolehan nilai rata-rata keaktifan belajar dalam satu kelas hanya sebesar 10, kemudian pada siklus I menunjukkan adanya peningkatan kriteria cukup aktif dibuktikan dengan perolehan nilai rata-rata keaktifan peserta didik sebesar 15,11 . Selanjutnya pada siklus II menunjukkan kriteria aktif dibuktikan dengan perolehan nilai rata-rata keaktifan belajar sebesar 20,44. kemudian pada siklus III menunjukkan kriteria sangat aktif dengan hasil sebesar 24,44 .

\section{SIMPULAN}

Penerapan pendekatan saintifik dapat meningkatkan keaktifan belajar pada sub tema 1 ciri-ciri makhluk hidup peserta didik kelas 3 SDN 2 Dimoro tahun ajaran 2020/2021. Keaktifan belajar Peserta didik pada pelaksanaan pra siklus menunjukkan kriteria kurang aktif, kemudian pada siklus I menunjukkan kriteria cukup aktif. Selanjutnya pada siklus II menunjukkan kriteria aktif kemudian pada siklus III menunjukkan kriteria sangat aktif. Ditunjukkan dengan perubahan perilaku peserta didik yang mengalami peningkatan pada setiap siklusnya yaitu: (a) siap mengikuti pembelajaran dengan penuh semangat; (b) memperhatikan tayangan materi yang ditampilkan oleh guru; (c) saling bekerjasama dalam kegiatan diskusi kelompok; (d) percaya diri ketika mempresentasikan hasil diskusi kelompok; (e) menghargai pendapat atau hasil diskusi teman (f) menyimpulkan hasil diskusi; (h) mengerjakan tugas evaluasi.

Dengan demikian maka hipotesis tindakan telah terbukti bahwa Penerapan pendekatan saintifik dapat meningkatkan keaktifan belajar pada sub tema 1 ciri-ciri makhluk hidup peserta didik kelas 3 sdn 2 dimoro tahun ajaran 2020/2021. 
Penerapan pendekatan saintifik dapat meningkatkan keaktifan belajar pada sub tema 1 ciri-ciri makhluk hidup peserta didik kelas 3 SDN 2 Dimoro tahun ajaran 2020/2021. Keaktifan belajar Peserta didik pada pelaksanaan pra siklus menunjukkan kriteria kurang aktif, kemudian pada siklus I menunjukkan kriteria cukup aktif. Selanjutnya pada siklus II menunjukkan kriteria aktif kemudian pada siklus III menunjukkan kriteria sangat aktif. Ditunjukkan dengan perubahan perilaku peserta didik yang mengalami peningkatan pada setiap siklusnya yaitu: (a) siap mengikuti pembelajaran dengan penuh semangat; (b) memperhatikan tayangan materi yang ditampilkan oleh guru; (c) saling bekerjasama dalam kegiatan diskusi kelompok; (d) percaya diri ketika mempresentasikan hasil diskusi kelompok; (e) menghargai pendapat atau hasil diskusi teman (f) menyimpulkan hasil diskusi; (h) mengerjakan tugas evaluasi.

Dengan demikian maka hipotesis tindakan telah terbukti bahwa Penerapan pendekatan saintifik dapat meningkatkan keaktifan belajar pada sub tema 1 ciri-ciri makhluk hidup peserta didik kelas 3 sdn 2 dimoro tahun ajaran 2020/2021.

\section{DAFTAR PUSTAKA}

Kusumah, Wijaya dan Dedi Dwitagama, (2010). Mengenal Penelitian Tindakan Kelas. Edisi: 2. Jakarta: PT Indeks.

Martinis Yamin, (2007). Kiat Membelajarkan Siswa. Jakarta: Gaung Persada Press dan Centar For Learning Innovation (CLI).

Nana Sudjana, (2004). Dasar-Dasar Proses Belajar Mengajar. Bandung: Sinar Baru Algessindo.

Oemar, Hamalik, (2013). Proses Belajar Mengajar. Jakarta: Bumi Aksara.

Paizaluddin dan Ermalinda, (2016). Penelitian Tindakan Kelas (Classroom Action Research). Bandung: Alfabeta.

Rohani, Ahmad, (2010). Penggelolaan Pengajaran. Jakarta: Rineka Cipta.

Sanaky, Hujair, AH, (2013). Media Pembelajaran Interaktif-Inovatif. Yogyakarta: Kuakaba Dipantara.

Sugiyono, (2014). Metode Penelitian Pendidikan (Pendekatan kuantitatif, kualitatif). Bandung: Alfabeta.

Sugiyono, (2016). Metode Penelitian Pendidikan Pendekatan kuantitaf, kualitatif, dan $R \& D$. Bandung: Alfabeta. 